PII S0145-2134(99)00132-5

\title{
DIFFERENTIATING INCEST SURVIVORS WHO SELF-MUTILATE
}

\author{
SusAn C. TURell \\ University of Houston-Clear Lake, Houston TX, USA
}

MARY W. ARMSWORTH

University of Houston, Houston, TX, USA

\begin{abstract}
Objective: This study was an exploratory analysis of the variables which differentiated incest survivors who self-mutilate from those who do not.

Method: A sample of women incest survivors $(N=84)$ were divided into two groups based on the presence or absence of self-mutilation. Participants included both community and clinical populations. A packet consisting of a demographic questionnaire, Sexual Attitudes Survey, Diagnostic Inventory of Personality and Symptoms, Dissociative Events Scale and the Beck Depression Inventory was completed by each participant.

Results: Demographic, incest, and family of origin variables distinguished the self-mutilating women from those who did not. These include ethnicity and educational experiences; duration, frequency, and perpetrator characteristics regarding the incest; and multiple abuses, instability, birth order, and loss of mother in one's family of origin. Psychological and physical health concerns also differentiated between the two groups.

Conclusions: Many variables may differentiate between women incest survivors who self-mutilate from those who do not. A rudimentary checklist to describe the lives of incest survivors who self-mutilate resulted from these findings. The importance of the concept of embodiment is also discussed. (C) 2000 Elsevier Science Ltd
\end{abstract}

Key Words-Self-mutilation, Incest, Checklist, Adult women.

INCEST AND SELF-MUTILATION have been linked in the recent research literature. Some studies have noted incest in the history of women who self-mutilate, while others have observed self-mutilation as a symptomatic behavior of some incest survivors. Studies by Goldney and Simpson (1975), Grunebaum and Klerman (1967), and Simpson and Porter (1981) all found connections between self-mutilation and sexual abuse perpetrated by parents. Percentages of incest survivors who self-mutilate range from 17\% (Briere \& Zaidi, 1989) to 58\% (de Young, 1982). Summit (1983) considered self-mutilation as one of the adaptive methods developed to survive and accommodate the secrecy, helplessness and entrapment of the sexual abuse. More recently, self-mutilation by incest survivors has been conceptualized as a symptom of Post Traumatic Stress Disorder (PTSD) (Albach \& Everaerd, 1992). In their study, 25\% of incest survivors meeting the criteria for PTSD also self-mutilated. While the link between an incest history and self-mutilation

Submitted for publication October 23, 1998; final revision received April 14, 1999; accepted April 26, 1999.

Requests for reprints should be sent to Susan C. Turell, PhD, University of Houston-Clear Lake, 2700 Bay Area Boulevard, Box 326, Houston, TX 77058. 
behavior has been well established in the literature, many questions remain unanswered. Although many self-mutilators have incest histories, not all incest survivors self-mutilate. Only one study (Turell \& Armsworth, submitted for publication) has explored the interrelation of variables that lead to an understanding of why some incest survivors self-mutilate while others do not. Over 20 variables suggested by previous studies were considered for inclusion in a log-linear model. Ultimately, four variables differentiated between the two groups of incest survivors. Those who self-mutilated exhibited greater current (1) dissociation and (2) depression, and were more likely to report past histories of (3) anorexia and/or bulimia and (4) physical and/or physiological abuse in their families of origin.

Many variables suggested by the literature were not included in the best-fitting log-linear model (Turell \& Armsworth, submitted for publication). Although excluded statistically, they are still interesting to consider as part of a descriptive study of women with incest histories who selfmutilate. In addition, other data collected examined variables that the literature has yet to consider. Using data first examined by the statistical log-linear model, the purpose of this study was to continue the exploration of this area of focus by descriptively eliciting several variable themes which differentiated the two groups.

This study utilized an expanded version of Ellenson's (1986) definition of incest, which was defined as any sexual contact between the perpetrator and the victim in which the perpetrator violated a position of trust or authority, with the first occurrence of the sexual contact taking place when the victim was less than 18 years old. This definition was purposefully broad for two reasons. First, the violation of trust by a person in a position of authority is a key variable when examining the psychological impact of trauma, and is more relevant in many ways than the degree of family or blood relation. Second, the exploratory nature of the research permitted a more broad inclusiveness in eliciting data.

For the purposes of this research, an expansion of the Walsh and Rosen (1988) definition of self-mutilation was developed. Self-mutilation behavior was defined as the conscious intent to harm oneself by a repetitive pattern of low lethality, socially unacceptable behavior which resulted in the actual physical alteration of the body.

\section{METHOD}

\section{Procedure}

Data were obtained as part of a comprehensive research project of 1,000 males and females on various aspects of psychosocial experiences. Participants completed a materials packet which included demographic and descriptive questionnaires, as well as the assessment instruments for the study. The packets were distributed in university and community college classes, through peer and therapy groups at community mental health clinics, and to individuals with incest histories identified by therapists. All data was collected anonymously.

\section{Participants}

All females who reported a history of incest and who had engaged in self-mutilation were included in this study. Incest survivors who had not self-mutilated were selected at random from the available remaining sample to constitute a comparison group for the present study. The presence or absence of self-mutilation behavior was used to assign the participants into two groups.

The sample included 84 women, with each group consisting of 42 women. The range of age was 18 to 67 years, with a mean age of $32.48(S D=9.69)$. The median age was 32 years.

Sixty-six $(78.6 \%)$ of the participants were Caucasian. This ethnically diverse sample included 10 
(11.9\%) Latinas, 4 (4.8\%) African-Americans, 2 (2.4\%) Asians, and 2 (2.4\%) women who identified themselves as bi- or multi-ethnic.

Fifty-two (62.65\%) women in the sample had attended or completed college, 19 (22.6\%) had attended or completed a graduate level education, and $13(15.5 \%)$ women terminated their formal education before attaining or with attainment of a high school diploma. Over half $(n=46 ; 54.7 \%)$ of the women personally earned less than $\$ 15,000$ a year, while $19(22.6 \%)$ earned over $\$ 25,000$ a year.

\section{Instruments}

All prospective participants received a packet of materials in a stamped return envelope which included an introductory letter, informed consent conditions, instructions, and questionnaires.

Demographic questionnaire. The demographic questionnaire was developed for the purposes of this research to gather basic factual information regarding current and historical life experiences as remembered by the participant.

Sexual Attitudes Survey. This six item survey was developed by David Finkelhor (Finkelhor, 1980), a well-known researcher in the area of sexual abuse. It is designed to measure attitudes on sex and body image. The reliability and validity are not well established.

Diagnostic Inventory of Personality and Symptoms (DIPS). The DIPS (Vincent, 1985) is a 171 item inventory which yields information on 14 scales. The items were developed from the descriptors and criteria of the DSM-III diagnostic categories for Axis I and II. Elevations above a $T$ score of 70 are used to derive profile types. The DIPS has demonstrated high test/retest reliability (Vincent, 1987) and both content and criterion-referenced validity (Vincent, 1987; Vincent \& Duthie, 1986).

Dissociative Events Scale (DES). The DES, developed by Bernstein and Putnam (1986), is a 28 -item instrument that measures dissociative phenomena. The score is derived from the average of the responses to the items, each consisting of a statement in which the respondent is asked to indicate what percentage of the time the described phenomena happened to them. The DES has been demonstrated to be both a reliable and valid instrument to assess dissociation (Bernstein \& Putnam, 1986; Ross, Joshi, \& Currie, 1990).

Beck Depression Inventory (BDI). This inventory assesses 21 categories of symptoms and attitudes related to clinically observed depression. Updated in 1978, the instrument continues to demonstrate high levels of internal reliability and validity (Beck \& Steer, 1984; Beck, Steer, \& Garbin, 1988).

\section{RESULTS}

\section{Demographic Themes: Ethnicity, Education, Career, and Finances}

Demographic themes did emerge around ethnicity and education/career/income variables. Women of color were less likely to report self-mutilation than Caucasian women. Caucasian women constituted $78.6 \%$ of the sample, yet comprised $85.7 \%$ of the self-mutilators. Other ethnic variations emerged, such that the percentages of participants within each group reporting selfmutilation varied: Latinas-20\% $(n=10)$, African-Americans-25\% $(n=4)$, Caucasians-45\% $(n=66)$, Asian-Americans-100\% $(n=2)$. Of course, with such small $N$ s in some groups, these trends are only speculative. However, further investigation would be useful to explore if these 
Table 1. Incest Perpetrator Variables

\begin{tabular}{lcc}
\hline & $\begin{array}{c}\text { Self-mutilators }(N=42) \\
\text { Mean }(S D)\end{array}$ & $\begin{array}{c}\text { Non-mutilators }(N=42) \\
\text { Mean }(S D)\end{array}$ \\
\hline Perpetrators (Total) & $2.86(2.0)$ & $1.76(1.13)$ \\
$\quad$ Family & $1.72(1.22)$ & $1.36(.82)$ \\
$\quad$ Non-family & $1.88(1.41)$ & $1.67(1.29)$ \\
Age of perpetrator & & $11(4.35)$ \\
$\quad$ Family & $19.18(7.35)$ & $23(7.68)$ \\
$\quad$ Non-family & $34.44(19.56)$ & \\
\hline
\end{tabular}

differences are an artifact of the small subsamples, or are indicative of actual inter-ethnic differences.

Educational differences also emerged between the two groups. Self-mutilators were more likely to report learning problems in school $(40.5 \%)$, compared to $16.7 \%$ of the non-mutilators. Problems with teachers $(66.7 \%$ to $23.8 \%)$ and failing grades $(23.8 \%$ to $11.9 \%)$ were also reported more frequently.

This translated to lower levels of educational achievement. Survivors who self-mutilate were more likely to stop at a high school education $(21.4 \%$ to $8.5 \%)$ and less likely to attend graduate school (16.7\% to $29.6 \%$ ). Interestingly, this lower educational level did not translate to lower economic potential. Self-mutilators on the whole reported higher income levels than the nonmutilators. Self-mutilators more often reported making more than $\$ 25,000$ (28.6\% to $16.7 \%)$. These percentages were identically reversed in the 0-\$999 per year category. Using Holland's occupational codes (Zunker, 1986), they were more likely to be employed in Realistic, Enterprising, or Conventional careers when compared to the non-mutilators. They were less likely to be employed in the Investigative or Social career areas. Perhaps these career areas explain the higher income levels. There were no differences in unemployment rates.

\section{Incest Variables: Perpetrators and Severity Variables}

Several themes related to the perpetrator of the incest seem to be associated with the presence of self-mutilation. The results related to perpetrator characteristics are found in Table 1. Ensick (1992) found that a history of multiple perpetrators was significantly related to increases in self-mutilation. Findings from this study supported this trend. Patterns emerged suggesting that older perpetrators were also related to self-mutilation. Parents were more frequently a perpetrator for the self-mutilating group. Fathers were an offender for $51.3 \%$ of the self-mutilating group, compared to $25 \%$ of the non-mutilating group (Turell \& Armsworth, submitted for publication). Mothers, too, were more likely to have been an offender for the self-mutilation group of survivors ( $10.3 \%$ to $2.8 \%)$. These results are consistent with previous research by both Friedrich, Urquiza, and Beilke (1986) and Briere and Runtz (1988).

In this study, both duration and frequency of the sexual abuse were indicative of self-mutilation. The average duration of the incest of the self-mutilating group was almost double (6.83 years, $S D=6.25$ ) that of the non-mutilating group (3.97 years, $S D=6.31$ ). These results are consistent with previous research about the relation of longer duration and severity of incest by Briere and Runtz (1988), Friedrich and colleagues (1986), and Morrow and Sorell (1989).

Lengthy duration is consistent with greater frequency of abuse; therefore, it's no surprise that the self-mutilators reported greater frequency as well. When asked for an estimate regarding the number of incidents, the self-mutilating group reported 22 non-familial sexual incidents and 45 familial ones. Women who did not self-injure remembered 10.8 and 38.44 incidents, respectively (Turell \& Armsworth, submitted for publication). In another section of the questionnaire, participants were asked to choose one of several standardized answers regarding frequency (choices were 
once, 2-3 times, 4-5 times, and 6+ times). For family perpetrators, the most frequent category $(6+)$ was endorsed by $51.4 \%$ of the self-mutilators compared to $31.4 \%$ of the non-mutilators. The same pattern was evident for the non-family perpetrators; $44.4 \%$ of self-mutilators compared to $31.8 \%$ of non-mutilators endorsed the $6+$ category.

Although penetration is often hypothesized to be more traumatic for the victim (Friedrich et al., 1986; Zweig-Frank, Paris, \& Guzder, 1994), the types of sexually abusive acts did not differentiate between the two groups in this study.

Therefore, the incest experienced by women who self-mutilate is more likely to include parental perpetrators as one of multiple older offenders, resulting in longer duration and frequency of the abuse.

\section{Family of Origin Variables: Abuses, Instability, Family Constellation and Loss of Mom}

As indicated in the log-linear model (Turell \& Armsworth, submitted for publication), the presence of additional types of abuse differentiated between the two groups. The mean number of abuses reported by self-mutilators was 3.17, while non-mutilators reported 2.07. These types of abuse included family sexual, non-family sexual, physical abuse by family members and physiological abuse by family members.

For each abuse category, the self-mutilating group reported greater frequency and a wider variety of specific abusive acts. Fifty-three percent of the self-mutilators reported continuous physical abuse as a child, and $41 \%$ reported continuous abuse as an adolescent. The percentages for non-mutilators were $30.4 \%$ and $17.4 \%$ for those same categories. For every physically abusive act, the self-mutilators reported greater frequencies; these included being hit with an open hand, hit with a fist, hit with an object, kicked, choked, having hair pulled, and being restrained. This abuse resulted in more severe injuries for the self-mutilators: one-third had injuries which required medical attention, compared to none of the non-mutilators. A history of physical abuse for self-mutilators is consistent with the research by Bach-y-Rita (1974), Carroll, Schaffer, Spensley, and Abramowitz, (1980, 1981), Ensick (1992), Simpson and Porter (1981), and Walsh and Rosen (1988).

The self-mutilators were more often physically abused by older, more powerful relatives. The physical abuse was more often perpetrated by the mother $(61.5 \%)$ and father $(66.7 \%)$ for the self-mutilators, compared to $43.5 \%$ and $56.5 \%$, respectively, for the non-mutilating group. The self-mutilating group also reported physical abuse by grandparents, although none of the nonmutilating group reported this. Of those who were physically abused, the non-mutilating group reported brothers, sisters and stepfathers in greater frequencies than the self-mutilators. On a scale of 0 to 100, the mutilators also rated the physical abuse as more upsetting $(M=85, S D=26.8)$ and more damaging $(M=87.3, S D=20.8)$ than did the non-mutilators, with means of $71.1(S D=$ $33)$ and $61.4(S D=33.9)$, respectively.

Reports of sexual abuse before the age of 18 by non-family members were made by $69 \%$ of the self-mutilators. These incidents were slightly more than reported by non-mutilators $(54.8 \%)$. The types of offenders did not vary much, with the exception of the stranger category, reported by $44.8 \%$ of the self-mutilators compared to $17.4 \%$ of the non-mutilators. Self-mutilators were younger on average when the abuse started/happened ( 7.7 years) than the non-mutilators (10.4 years). Not surprisingly, on the 0 to 100 scale rating, once again they found it more upsetting $(M=$ $78.9, S D=30.2)$ and more damaging $(M=82.4, S D=28)$ than the non-mutilators (upsetting: $M=54.1, S D=38.9$; damaging: $M=54.1, S D=38.9$ ).

The participants reporting physiological abuse were overwhelming in the self-mutilator group ( $n=26,61.9 \%)$. Only five $(11.9 \%)$ of the non-mutilators reported this type of abuse. Examples of this abuse include being given drugs to sleep or calm down, being force fed or food withheld, given enemas or laxatives. The self-mutilators reported abusers in all categories of family members. The 
Table 2. Family of Origin Variables

\begin{tabular}{|c|c|c|}
\hline & $\begin{array}{l}\text { Self-mutilators } \\
\qquad \begin{array}{c}(N=42) \\
(\%)\end{array}\end{array}$ & $\begin{array}{c}\text { Non-mutilators } \\
\begin{array}{c}(N=42) \\
(\%)\end{array}\end{array}$ \\
\hline Parental Unemployment for Long Time & 24.0 & 12.0 \\
\hline Parental Abuse of Drugs/Alcohol & 17.0 & 7.0 \\
\hline Moved 4+ Times in Childhood & 43.0 & 12.0 \\
\hline Parents Divorced & 16.7 & 31.0 \\
\hline Participant is Only Child & 5.0 & 0 \\
\hline Participant is First Born & 17.1 & 29.7 \\
\hline Sibling Death as Child & 7.0 & 0 \\
\hline Favorite Pet Death as Child & 76.0 & 55.0 \\
\hline Illness or Injury of Father (During Childhood) & 26.2 & 26.2 \\
\hline Father's Death During Childhood & 9.5 & 14.3 \\
\hline Mother's Death During Childhood & 7.1 & 2.4 \\
\hline Illness or Injury of Mother (During Childhood) & 38.1 & 31.0 \\
\hline \multicolumn{3}{|l|}{ Throughout Childhood Felt } \\
\hline Abandoned by Mother & 59.5 & 28.6 \\
\hline Ignored by Mother & 31.0 & 11.9 \\
\hline Abandoned by Father & 64.0 & 41.0 \\
\hline Ignored by Father & 48.0 & 26.0 \\
\hline
\end{tabular}

non-mutilators reported only their mothers as the perpetrator. Once more, the self-mutilators rated the abuse as more upsetting $(M=78.6, S D=27)$ and more damaging $(M=75.2, S D=24.9)$ than the non-mutilators (upsetting: $M=61.2, S D=31.7$ and damaging: $M=70, S D=20$ ). Physiological abuse in one's family of origin has not been addressed in previous studies; its high frequency for self-mutilators warrants an closer look at this phenomenon.

There is evidence of greater emotional abuse sustained by the self-mutilators as well. They were nine times as likely to feel not wanted by their family, 10 times more likely to feel a burden to their family, five times as likely to wish they hadn't been born, twice as likely to feel isolated and alone, and over three times more likely to identify as the family scapegoat. Three-fourths of the self-mutilators felt no one loved them, compared to $43 \%$ of the non-mutilating group.

Instability was also a hallmark for the childhood years of the self-mutilators, as indicated in their family of origin experiences (Table 2). The self-mutilators reported higher rates of parental unemployment, substance abuse, and frequent moves, yet less divorce. The result, in effect, would be the maintenance of an intact family but one so abusive and dysfunctional that a child would have no relief from the horror.

There were no differences in the number of siblings in each groups' families. However, some patterns did emerge regarding birth order (Table 2). These findings suggest that if the women who self-mutilate were the first born in their family, the parents were less likely to have more children than parents of women who do not mutilate themselves. This may explain the increase in types, frequency and duration of the abuses for some of the self-mutilators: There were no other children in the family to abuse.

In addition, the self-mutilators reported more sibling deaths and deaths of favorite pets than the non-mutilating group (Table 2). Given the amount of abuse that occurred in these families, these reported deaths raise chilling questions about their causes. Killing of pets can be one way of threatening the victim into cooperation and silence (Courtois, 1988). Also, the escalation of family violence can result in homicide (Walker, 1984). Perhaps in these dysfunctional families, other victims did not survive the abuses.

The data obtained in this study creates a global picture of extreme dysfunction in the families of origin of the incest survivors who self-mutilate. Sexual, physical, and physiological abuses were rampant during the childhood and adolescent years of these survivors. When perpetrated on 
Table 3. Adult Violent Experiences

\begin{tabular}{lcr}
\hline & $\begin{array}{c}\text { Self-mutilators } \\
(N=38) \\
(\%)\end{array}$ & $\begin{array}{c}\text { Non-mutilators } \\
(N=41) \\
(\%)\end{array}$ \\
\hline Attempted Stranger Rape & 31.6 & 17.1 \\
Stranger Rape & 10.5 & 4.9 \\
Attempted Acquaintance Rape & 44.7 & 9.8 \\
Acquaintance Rape & 26.3 & 12.2 \\
Attempted Date Rape & 26.3 & 14.6 \\
Date Rape & 23.7 & 14.6 \\
Attempted Marital Rape & 18.4 & 14.6 \\
Marital Rape & 21.1 & 12.2 \\
Battering by Date & 21.1 & 12.2 \\
Battering by Spouse & 31.6 & 17.1 \\
Robbed & 31.6 & 31.7 \\
Robbed at Gunpoint & 18.4 & 4.9 \\
Attacked & 39.5 & 12.2 \\
\hline
\end{tabular}

self-mutilators, these abuses were more likely to be committed by parents, continue for longer duration and with greater frequency than for the non-mutilators. Keeping in mind the incest history of all the participants in the study, these findings suggest a childhood filled with even greater torture, danger and despair for those who self-mutilate as adults. The loss of a parent at a young age, either through death or divorce, has been documented in much of the self-mutilation literature as a predisposing variable (Bach-y-Rita, 1974; Carroll et al., 1980, 1981; Kahan \& Pattison, 1984; Simpson, 1977; Simpson \& Porter, 1981; Walsh \& Rosen, 1988). The results of this study were mixed regarding loss of a parent (Table 2). The results regarding death of one's father were the opposite of the findings suggested by the literature. The loss of one's mother, however, yielded a pattern consistent with the literature.

More subjectively, each participant was asked to indicate if, and for what time period, they felt ignored or abandoned by each parent (Table 2). All these results are consistent with previous research by Shapiro (1987), Simpson (1977), and Simpson and Porter (1981).

For the women in the self-mutilating group, the abuses did not stop with adulthood. They have been violently assaulted as adults about twice as often as the non-mutilating group (Table 3 ). These findings are consistent with revictimization associated with childhood sexual abuse (Beitchman et al., 1992).

\section{Idiosyncratic Meaning of Abuses}

Research conducted by Tsai, Feldman-Summers, and Edgar (1979) suggested that the survivor's idiosyncratic perception of negative impact would be associated with greater trauma. Much of the data collected in this study lends support for this observation. It is important to remember that the non-mutilators also experienced incest; consequently, their childhood or adolescent years were also traumatic. Consistently, however, the self-mutilators perceived their abuse as having a more negative impact than did the non-mutilators. Self-mutilators rated the incest as more upsetting $(M=79, S D=31)$ and more damaging $(M=88, S D=22)$ than the non-mutilating group (upset: $M=68, S D=30$; damage: $M=71, S D=56$ ). As noted above, for every other type of abuse reported, the self-mutilators scored themselves as being more upset and sustaining more damage than the non-mutilators.

In addition, the self-mutilators used words such as "sad," "troubled," "chaotic," "violent," "confusing," "frightening," and "terrifying" to describe their family during childhood and adolescence as much as two to three times more frequently than non-mutilators. Internalized messages of humiliation and shame, parentification as a child, punishment or ridicule for exhibiting emotions, 


\begin{tabular}{lcc}
\hline & $\begin{array}{c}\text { Self-mutilators } \\
(N=42)\end{array}$ & $\begin{array}{c}\text { Non-mutilators } \\
(N)\end{array}$ \\
& $(\%)$ & $(\%)$ \\
\hline Suicidal Thoughts & & 71.4 \\
Suicide Attempts & 92.9 & 14.3 \\
Depression as Child or Adolescent & 54.8 & 38.1 \\
Depression Score Clinically Elevated on DIPS & 76.2 & 30.0 \\
Memory Loss & 43.9 & 26.2 \\
Amnesia & 54.8 & 2.4 \\
Difficulty Remembering Periods of One's Life & 11.9 & 59.5 \\
Drug or Alcohol Use as Child & 83.3 & 14.3 \\
Drug or Alcohol Use as Adolescent & 31.0 & 54.8 \\
Problems with Drugs or Alcohol & 83.3 & 33.3 \\
Treatment for Drugs or Alcohol & 57.2 & 4.8 \\
Substance Abuse Illness & 19.0 & 16.7 \\
Anorexia & 33.3 & 4.8 \\
Bulimia & 19.0 & 0 \\
Obesity & 19.0 & 33.3 \\
Anxiety-Adult & 28.6 & 40.5 \\
Anxiety-Child/Adolescent & 81.0 & 31.0 \\
Panic Attacks & 76.2 & 19.0 \\
Anxiety Score Clinically Elevated on DIPS & 54.8 & 17.5 \\
Phobias & 56.1 & 26.2 \\
Recurrent Nightmares & 45.2 & 38.1 \\
Visual Hallucinations & 69.0 & 9.5 \\
Auditory Hallucinations & 14.3 & 4.8 \\
Paranoid Psychosis Score Clinically Elevated on DIPS & 19.0 & 30.0 \\
Schizophrenic Psychosis Score Clinically Elevated on DIPS & 43.9 & 30.0 \\
\hline
\end{tabular}

expectations of perfection, feelings of abandonment, rejection, isolation, and being unloved were reported more frequently by the incest survivors who self-mutilated. All these findings support the importance of an idiosyncratic meaning for the survivor in the determination of trauma rather than specific facts about the incest. The centrality of the subjective perception in relation to trauma validates theoretical assumptions advanced by Freyd (1996) and McCann and Pearlman (1990) regarding disrupted schema experienced by traumatized individuals and its affect on their world view.

\section{Psychological Issues}

The log-linear model (Turell \& Armsworth, submitted for publication) which best fit the data for self-mutilation included three psychological variables: depression, current dissociation, and a history of anorexia and/or bulimia. Depression was measured by the Beck Depression Inventory (BDI). The scores of the self-mutilators ranged from 1 to 41, with a mean score of 20.67 ( $S D=$ 11.47). This mean falls in the upper range of moderate depression (Vincent, 1987). Ranging from 1 to 27 , the mean score for the non-mutilators was $10.5(S D=7.07)$, which was at the insignificant depression level (Vincent).

Table 4 contains several measures of psychological functioning, including self-reports of depression, anxiety, dissociation, substance use and eating disorders. In addition, it includes comparisons of some relevant elevated clinical scores on the DIPS. Findings in this study (Table 4) on suicidal ideation, suicidal attempts and depression are consistent with those of previous research, in which depression was associated with self-mutilation (Brodsky, Cloitre, \& Dulit, 1995).

Dissociation has also been correlated with self-mutilation in the literature (Bach-y-Rita, 1974; Brodsky et al., 1995; Greenspan \& Samuel, 1989; Pao, 1969; Simpson, 1975; Waltzer, 1968). 
Turell and Armsworth (submitted for publication) used the Dissociative Events Scale (DES) to measure current dissociation. The mean score of the self-mutilators was $26.93(S D=19.6)$ compared to 12.7 ( $S D=9.23$ ) of the non-mutilators, and was one of four variables in the log-linear model to differentiate between groups. In addition, questions about memory loss, amnesia and difficulty in remembering periods of one's life solicited information about past dissociation, again consistent with previous research (Table 4).

As a dissociative method, substance abuse has been associated with self-mutilation behavior by a number of investigators (Ensick, 1992; Kahan \& Pattison, 1984; Pattison \& Kahan, 1983; Simpson, 1975). The findings in Table 4 indicate that self-mutilators report more substance use/abuse. Also, differences emerged regarding body image disturbances (Table 4). There was no difference between the two groups on obesity. Related to eating disorders are body image distortions. In rating the statement "I really like my body" on the Sexual Attitudes Survey (SAS) by Likert scale, $60 \%$ the self-mutilators endorsed it "not true of me," compared to $43 \%$ of the non-mutilating group. At the other end of the scale, only 5\% endorsed the item as "extremely true of me," compared to $19 \%$ of the non-mutilating group.

Sexual disturbances of various types have been associated with self-mutilation (Goldney \& Simpson, 1975; Pao, 1969; Simpson, 1977; Walsh \& Rosen, 1988). The item "After sexual experiences, I usually feel dissatisfied" on the SAS was rated as "extremely true of me" by $31 \%$ of the self-mutilators, compared to only $5 \%$ of the non-mutilating group.

Lastly, several anxiety-related psychological problems were experienced by the self-mutilators in greater frequency than the non-mutilators as were elevated scores on two psychosis scales (Table 4).

\section{Physical Health Concerns}

As a group, the self-mutilators suffered more illnesses than the non-mutilators. The most notable of these were allergies, anemia, endometriosis, epilepsy, headaches (including migraines), pelvic pain, shingles, lupus, ulcers, substance abuse, and TMJ, all of which the mutilator group experienced in approximately double or more the frequency of the non-mutilators. The mutilators also reported double the number of miscarriages compared to the non-mutilating group. The Somatoform Disorders scale of the DIPS concurs with these findings; $43.9 \%$ of the self-mutilators had elevated scores on this scale, compared to $22.5 \%$ of the non-mutilating group. Forty-eight percent of the self-mutilators had elevated scores on the Psychological Conditions Affecting Physical Conditions scale, while only $20 \%$ of the non-mutilating group had elevated scores on this scale.

\section{DISCUSSION}

\section{Embodiment}

Embodiment refers to how the self "is experienced in and through the body" (Young, 1992, p. 90). Young suggested that embodiment may be a key concept to understanding many phenomena related to child sexual abuse. Because trauma/ abuse involves a threat to one's survival and physical integrity, the trauma may be "inscribed in and often on the bodies of survivors" (p. 91). Since the body is crucial to our experiences of ourselves in the world, the violation of the boundary of one's body can have severe repercussions, and may actually threaten one's sense of existence. If the survivor can relegate the focus of the abuse to the body, they can exercise some control over painful feelings and memories, thereby separating from them. Hence, there is an increased probability of dissociation from one's body. Self-mutilation can then serve the dual purposes of punishing the body as well as helping to counter dissociative tendencies by grounding oneself.

Several of the findings in this study indicate the importance of this concept of embodiment in 
understanding the dynamic of self-mutilation for some incest survivors. Many variables that seem to differentiate between two groups are related to embodiment. Those related to the presence of self-mutilation include:

- the increased likelihood of physical and physiological abuses in one's family of origin history of anorexia and/or bulimia

- body image distortions

- somatization and increased medical concerns

- dissociation/depersonalization.

All these variables indicate that a key differentiation of survivors who self-mutilate may be their special relationship, or even a preoccupation, with their bodies. While causality cannot be claimed, perhaps the additional abuses in the families of origin create a focus on the body in a way that may not be experienced through incest alone. That focus/preoccupation may then be evidenced by eating disorders, body image distortions, somatization, dissociation, and of course, self-mutilation, into adulthood. "Embodiment" may offer a key to understand why some incest survivors self-mutilate and others do not. The area should provide fertile ground for future research into the etiology of self-mutilation by some incest survivors.

\section{Clinical Implications: Healing and Therapy}

Given the greater psychological concerns throughout their lives, it is not surprising that many of the self-mutilators sought therapy. The women in the self-mutilating group reported seeking help more frequently from every classification of caregiver (psychiatrists, psychologist, social workers, ministers/priests, peer counselors, school counselors, and mental health counselors). They also sought more group therapy. Overall, the self-mutilators attended more sessions with these mental health caregivers than did the non-mutilators. Also, more self-mutilators were admitted to psychiatric hospitals (36\%) compared to non-mutilators (2\%). However, the effectiveness of these services is questionable, as the non-mutilators tended to rate the services received as more helpful overall.

Organized religion was not important to $69 \%$ of the women who self-mutilated, and they were less likely to report an affiliation with organized religion as adults. However, almost all (92.9\%) indicated that spirituality was very or somewhat important currently. One avenue for more effective interventions with this population might be the inclusion of a spiritual dimension to counseling or support. Andrews (1989) noted the importance of spirituality to overcome difficult emotional problems, such as depression, fear, worthlessness, guilt, loneliness, anxiety, and indecision. Many of these are feelings reported by self-mutilating incest survivors, therefore suggesting the inclusion of a spirituality dimension to affect more change in the counseling process with this group.

The results of this study, coupled with those of Turell and Armsworth (submitted for publication), suggest items that could be used in the development of a checklist of variables by which to assess both the possibility or actual practice of self-mutilation behavior by incest survivors (Appendix). A checklist of this type could facilitate mental health professionals' assessment of the risk their clients present regarding self-mutilation behavior. Since clients are reluctant to disclose these behaviors (de Young, 1982; Walsh \& Rosen, 1988), a checklist could alert therapists to look for certain patterns of historical facts and current behaviors and symptoms. An instrument of this type could be used with clients to encourage discussion about the self-mutilation, normalizing the behavior and reducing her feelings of isolation about its occurrence. Future research could be conducted to create a more psychometrically-sound checklist. Additional research is also needed to duplicate and confirm the discriminatory power of these variables regarding self-mutilation behavior of incest survivors. 


\section{Limitations of the Study}

The sample was generally well-educated and Caucasian, and a high percentage of the women in this study had therapy experience. As with many surveys, self-report bias may have operated. Conclusions drawn from these results must take into account the limitations of generalizability based on the demographics of the participants and the subjective nature of the responses. The BDI, DIPS, and DES all appear to be instruments having reasonable reliability and validity. However, the SAS has limitations as to how well it measured the intended variables regarding sexual functioning. Results using variables measured by the SAS should be interpreted cautiously.

\section{REFERENCES}

Albach, F., \& Everaerd, W. (1992). Posttraumatic stress symptoms in victims of childhood incest. Psychotherapy and Psychosomatics, 57, 143-151.

Andrews, L. (1989). To thine own self be true: The relationship between spiritual values and emotional health. New York: Doubleday.

Bach-y-Rita, G. (1974). Habitual violence and self mutilation. American Journal of Psychiatry, 131, 1018-1020.

Beck, A., \& Steer, R. (1984). Internal consistencies of the original and revised Beck Depression Inventory. Journal of Clinical Psychology, 40, 1365-1367.

Beck, A., Steer, R., \& Garbin, M. (1988). Psychometric properties of the Beck Depression Inventory: Twenty-five years of evaluation. Clinical Psychology Review, 8, 77-100.

Beitchman, J., Zucker, K., Hood, J., DaCosta, G., Akman, D., \& Cassavia, E. (1992). A review of the long-term effects of child sexual abuse. Child Abuse \& Neglect, 16, 101-118.

Bernstein, E., \& Putnam, F. (1986). Development, reliability, and validity of a dissociation scale. Journal of Nervous and Mental Disease, 174, 727-733.

Briere, J., \& Runtz, M. (1988). Symptomatology associated with childhood sexual victimization in a non-clinical adult sample. Child Abuse \& Neglect, 12, 51-59.

Briere, J., \& Zaidi, L. (1989). Sexual abuse histories and sequelae in female psychiatric emergency room patients. American Journal of Psychiatry, 146, 1602-1606.

Brodsky, B., Cloitre, M., \& Dulit, R. (1995). Relationship of dissociation to self-mutilation and childhood abuse in borderline personality disorder. American Journal of Psychiatry, 152, 1788-1792.

Carroll, J., Schaffer, C., Spensley, J., \& Abramowitz, S. (1980). Family experiences of self-mutilating patients. American Journal of Psychiatry, 137, 852-853.

Carroll, J., Schaffer, C., Spensley, J., \& Abramowitz, S. (1981). Family andecedents of adult self-mutilators. International Journal of Family Psychiatry, 2, 147-161.

Courtois, C. (1988). Healing the incest wound. New York: W. W. Norton and Co.

de Young, M. (1982). Self injurious behavior in incest victims: A research note. Child Welfare, 61, 577-584.

Ellenson, G. (1986). Disturbances of perception in adult female incest survivors. Social Casework, 67, $149-159$.

Ensick, B. (1992). Confusing realities: A study on child sexual abuse and psychiatric symptoms. Amsterdam: VU University Press.

Finkelhor, D. (1980). Sex among siblings: A survey report on its prevalence, variety, and effects. Archives of Sexual Behavior, 9, 171-194.

Freyd, J. (1996). Betrayal trauma. Cambridge, MA: Harvard University.

Friedrich, W., Urquiza, A., \& Beilke, R. (1986). Behavior problems in sexually abused young children. Journal of Pediatric Psychology, 11, 47-57.

Goldney, R., \& Simpson, I. (1975). Female genital self-mutilation, dysorexia and the hysterical personality: The Caenis syndrome. Canadian Psychiatric Association Journal, 20, 435-441.

Greenspan, G., \& Samuel, S. (1989). Self-cutting after rape. American Journal of Psychiatry, 146, 789-790.

Grunebaum, H., \& Klerman, G. (1967). Wrist slashing. American Journal of Psychiatry, 124, 527-534.

Kahan, J., \& Pattison, E. M. (1984). Proposal for a distinctive diagnosis: The deliberate self-harm syndrome (DSH). Suicide and Life-Threatening Behavior, 14, 17-35.

McCann, I., \& Pearlman, L. (1990). Vicarious traumatization: A framework for understanding the psychological effects of working with victims. Journal of Traumatic Stress, 3, 131-149.

Morrow, K. B., \& Sorell, G. (1989). Factors affecting self-esteem, depression, and negative behaviors in sexually abused female adolescents. Journal of Marriage and the Family, 51, 677-686.

Pao, P. (1969). The syndrome of delicate self-cutting. British Journal of Medical Psychology, 42, 195-206.

Pattison, E. M., \& Kahan, J. (1983). The deliberate self-harm syndrome. American Journal of Psychiatry, 140, 867-872.

Ross, C., Joshi, S., \& Currie, R. (1990). Dissociative experiences in the general population. American Journal of Psychiatry, 147, 1547-1552.

Shapiro, S. (1987). Self-mutilation and self-blame in incest victims. American Journal of Psychotherapy, 41, 46-54.

Simpson, C., \& Porter, G. (1981). Self-mutilation in children and adolescents. Bulletin of the Menniger Clinic, 45, $428-438$. 
Simpson, M. (1975). The phenomenology of self-mutilation in a general hospital setting. Canadian Psychiatric Association Journal, 20, 429-433.

Simpson, M. (1977). Self-mutilation and the borderline syndrome. Dynamische Psychiatrie, 10, 42-48.

Summit, R. (1983). The child sexual abuse accommodation syndrome. Child Abuse \& Neglect, 7, 177-193.

Tsai, M., Feldman-Summers, S., \& Edgar, M. (1979). Childhood molestation: Variables related to differential impacts on psychosexual functioning in adult women. Journal of Abnormal Psychology, 88, 407-417.

Turell, S. C., \& Armsworth, M. W. (submitted for publication). A log-linear analysis of variables associated with self-mutilation behaviors of women with incest histories.

Vincent, K. R. (1987). Full battery codebook: A handbook of psychological test interpretation. Norwood NJ: Ablex Publishing Corporation.

Vincent, K., \& Duthie, B. (1986). Factor structure of DIPS in a private psychiatric hospital population. Journal of Clinical Psychology, 42, 312-314.

Walker, L. (1984). The battered women syndrome. New York: Springer.

Walsh, B., \& Rosen, P. (1988). Self-mutilation: Theory, research and treatment. New York: Guilford Press.

Waltzer, H. (1968). Depersonalization and self-destruction. American Journal of Psychiatry, 125, 399-401.

Young, L. (1992). Sexual abuse and the problem of embodiment. Child Abuse \& Neglect, 16, 89-100.

Zunker, V. (1986). Career counseling: Applied concepts of life planning (2nd ed.). Monterrey CA: Brooks/Cole Publishing Co.

Zweig-Frank, H., Paris, J., \& Guzder, J. (1994). Psychological risk factors for dissociation and self-mutilation in female patients with borderline personality disorder. Canadian Journal of Psychiatry, 39, 259-264.

\section{APPENDIX}

\section{Sample Checklist to Assess for Self-mutilation Behavior by Women with Histories of Incest}

Check all that apply. Higher scores may be associated with increased risk for self-mutilation behavior.

\section{Demographics}

- I identify my ethnicity as Caucasian or European-American.

- I have not attended graduate school.

- My job is (Jobs in the conventional, realistic or enterprising categories may be associated with self-mutilation.)

\section{Abuses}

- I was sexually abused by more than one perpetrator.

- My perpetrator(s) was much older than me.

- My perpetrator was my mother and/or father.

- The sexual abuse lasted 6 or more years.

- The sexual abuse happened more than 6 times.

- I was physically abused in my family of origin.

- I was injured badly enough to be hospitalized.

- My parents or grandparents were the ones who physically abused me.

- I was sexually abused by a stranger as a child or adolescent.

- I was 8 or younger when that sexual abuse by a stranger happened.

- I was physiologically abused in my family of origin (e.g., force fed, given enemas, given drugs to sleep)

- I felt unwanted by my family.

- I felt like a burden to my family.

- I have felt that I wish I wasn't born.

- I was the family scapegoat.

- No one loved me in my family of origin.

- On a scale of 0 to 10 , these abuses were upsetting at a 7 or more. 
- On a scale of 0 to 10 , these abuses were damaging to me at a 7 or more.

Family of Origin

- One or both of my parents were unemployed for long periods of time during my childhood.

- One or both of my parents had alcohol or drug abuse problems when I was a child.

- We moved 4 or more times when I was a child.

- My parents were married throughout my childhood.

- I was an only child.

- I am not the oldest child.

- A brother or sister of mine died when I was a child.

- My favorite pet died during my childhood.

- My mother died when I was a child/adolescent.

- I was ignored by my mother and/or father as a child/adolescent.

- I felt abandoned by my mother and/or father as a child/adolescent.

\section{Mental and Physical Health}

- I am often depressed.

- I currently have symptoms of dissociation.

- I have been bulimic.

- I have been anorexic.

- I have thought about suicide often.

- I have attempted suicide.

- I was depressed as a child/adolescent.

- I suffer(ed) from memory loss.

- I suffer(ed) from amnesia.

- I have difficulty remembering periods of my life.

- I abused drugs/alcohol as a child/adolescent.

- I do not like my body.

- I am often dissatisfied after sex.

- I am anxious as an adult.

- I was anxious as a child/adolescent.

- I have panic attacks.

- I have phobias.

- I have recurrent nightmares.

- I have visual hallucinations.

- I have auditory hallucinations.

- I have been hospitalized for psychiatric problems.

- I have any of the following: (check all that apply) allergies, anemia, endometriosis, epilepsy, headaches, pelvic pain, shingles, lupus, ulcers, TMJ. 